\title{
A Framework for Analytical CRM Assessments Challenges and Recommendations
}

\author{
Maruthi Rohit Ayyagari \\ College of Business \\ University of Dallas, Texas \\ USA
}

\begin{abstract}
Businesses are increasingly adopting analytical customer relationship management (CRM) solutions. The critical customer information that resides within CRM can guide the decision-making process. Therefore, CRM analysis leads to higher loyalty and customer satisfaction, as well as enhanced competitive and financial performance. Data mining techniques are used to understanding customers and discovering interesting patterns. However, data mining techniques are considered a complicated process for non-technical decision makers and administrators. Therefore, the problem increases with the technical difficulty of large-scale CRM solutions for novice administrators and decision makers. This paper proposes a framework for the process of data mining in the context of analytical CRM to enhance the decision-making process. The paper also highlights the role of data mining in analytical CRM and how it assists the businesses to manage customer information better. The framework was evaluated and accepted by two senior CRM experts. The proposed framework revealed that there are still issues of customer data privacy and issues related to collected data types.
\end{abstract}

Keywords: Customer Relationship Management (CRM), Analytical CRM, CRM implementation, data mining, decision making

\section{Introduction}

In the business world, without catering to the needs of the customers, it is not possible for a business to survive amidst high competition (Hu et al., 2018). It is essential for a company to reach out to the right customer with the right offer at the right time. For this reason, companies are trying their best to make sure that the customers feel a sense of belongingness with them and remain as loyal customers for a more extended period. Customer Relationship Management (CRM) is an approach to managing the interaction of a company with current and potential customers. It is a set of techniques dedicated to analyzing, capturing, and processing customer data with the sole intention of building customer loyalty(Markovic et al., 2018).

A customer-centric strategy consists of three phases: planning, assessment, and execution (Plakoyiannaki \& Saren, 2006). The planning aims to develop plans for marketing, campaigns, sales, and engage customers. In the assessment phase, the customer selection is based on the analysis of customer data and his requirements. The later phase involves techniques of data warehousing, data mining, and online analytical processing (OLAP) technologies (Berson \& Smith, 1997). The data warehouse collects data from various resources such as sales, ERP, marketing, and customer data. The OLAP use embedded data mining algorithms to process data into cubes that could be utilized for decision makers. Finally, the execution phase carries out decisions that were taken based on previous reports generated by the assessment phase.

With the rapid advancements of information and communication technology (ICT), companies are now using data mining tools for customer segmentation (Tsiptsis \& Chorianopoulos, 2011), and profitability so that they can extract valuable customer information from the vast database and can successfully target the current and potential customers (Bhat \& Darzi, 2016). Data mining is also helping the firms to make knowledge-driven, proactive decisions that assist them in gaining a competitive advantage (Rygielski et al., 2002).

In the competitive market, companies must improve their customer relationship to optimize their profitability. Since customer expectations are evolving in the market, a qualified relationship experience is more important rather than a price or an attractive product (Zineldin, 2006). Strategic customer-based metrics such as recency, frequency, monetary value (RFM), past customer value, lifetime value metrics, and the customer equity are looking forward measures are further discussed in (Kumar \& Reinartz, 2018b). The problem is how we simplify the ICT techniques executed under the hood of CRM for decision makers who usually do not have extensive experience in the IT industry. 
A mass of work exists in which data mining models are used to solve business needs and predict customer expectations (Kaur \& Singh, 2018; Ngai et al., 2009; Tamayo et al., 2005; Tsiptsis \& Chorianopoulos, 2011). However, these models target the technical people, or they provide rigid rules without simplifying stuff for non-technical decision makers. The objective of this paper is to present a framework of analytical CRM as it related to many CRM components. The proposed model describes the ICT techniques as they are related to the decision makers to generate useful information.

This paper is organized as follows. Related works are summarized in Section two. Section three provides a ground base for analytical CRM concepts. Section four illustrates the proposed model. Section five provides discussions and discovered challenges, while section six concludes the paper.

\section{Related Work}

There are a great deal or related work in CRM analytics and data mining; however, little work targets non-technical people. The work of (Nam et al., 2019) tackles the dynamic marketing environment using dynamic capability applied with the emphasis on business analysis in CRM applications. They used a survey of 170 firms to find the relationship between IT competence and CRM performance. Similarity, to solve customer agility, the work of (Chatfield \& Reddick, 2018) proposed a theoretical framework for big data analytics-enabled customer agility and responsiveness was developed from extant IS research. They used a case study 311 governmental on-demand services and found a Big data analytics use by 22 departments embedded into critical processes. A solution by(Hamid et al., 2018) integrates social data of Institutions of Higher Learning (IHLs) in Malaysia into existing Customer Relationship Management (CRM) systems to produce a Social CRM Analytic model. They claimed that the model could asset assist IHLs in taking actions on the customers' problems or complaints. A review of the existing literature on Social CRM highlighted the need for data flow and strategy (Marques \& Costa, 2018).

At the University of Calgary, a collaboration project for Alberta Treasury Branches (ATB) uses analytical CRM with goal-question-metrics (GQM) understand customer needs(Hargreaves et al., 2018). The project engaged the Software Engineering and Decision Support (SEDS) laboratory of ATB to study and develop decision support tools to asset companies to manage their projects. The case study investigates the effect of software development process over adopted CRM implementations.

\section{Background of CRM}

\subsection{Data Management}

One of the main goals of CRM is the optimization of customer data management, especially with changing customer requirements, which expect more customizations (Anshari et al., 2018). Customers who interact through a website requesting a customer service should be recognized and provided with individualized responses to their requests. CRM and cloud computing are the technologies designed to centralize customer data management as it allows companies to respond effectively to customer requests. Simultaneously, the big data relies on the exploitation of massive data generated by the CRM channels to improve customer knowledge. CRM features are the foundation of a productive customer relationship that will benefit all stakeholders in the company far with the customer prospects. Features are adapted to the needs and challenges of the company, as well as its organization and its targets. CRM solutions will, therefore, primarily concern commercial teams (e.g., sales) as well as marketing teams, IT teams, and support or customer service teams (Figure 1). Centralized information within the CRM will, therefore, be shared by all the teams involved, in order to ensure optimal customer relationship management.

Manage company data and customer information and make it available for salespeople. The company focus on rewarding actions to improve the cross-sell and the up-sell. Saving the past actions or communications with customers enables companies to optimize marketing operations, eliminate inefficient tasks, continues to follow up of customers complaints. Consequently, business portfolios are administered with ease.

The progress of artificial intelligence is a real opportunity for brand products to improve its customer relationship, especially in aspects of the requirements, ultra-availability, immediacy, personalization, and fluidity. For example, machine learning and deep learning techniques are at the origin of a much better ability for chatbots and voice bots (Følstad et al., 2018). The automation, achievable through chatbots, allows for example to release human agents and free them for time-consuming tasks. It is also possible to integrate a redirection solution through these conversational agents to pass the relay to a human agent when the need arises, or to leave the choice to the customer. The same scenario can also occur on a website, where it is possible to integrate automatic redirection solutions to a call center. With these technologies, business owners can understand the natural language of customers and offer a more personalized conversation to customers. 


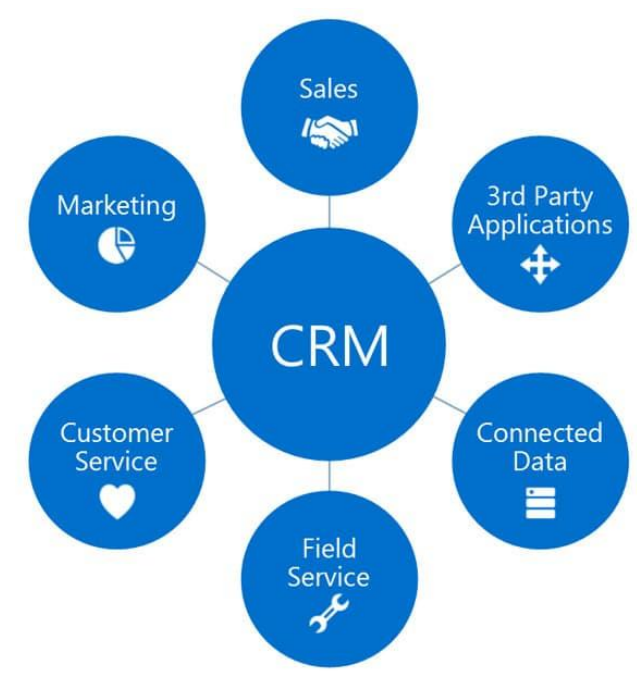

\section{Figure 1. Microsoft Dynamics CRM components}

The giants of CRM:Amazon, Airbnb, Netflix, and Uberdominate the market, with a success that comes less from their products or price, but rather from the experience they offer their customers (Tiwari \& others, 2018).Companies rely on customization to make a difference, but with a level that exceeds the expectations of the customer. On Amazon, suggestions are studied to fit perfectly with what interests' customers (Zhu, 2019). An art that the Netflix streaming platform also masters to perfection, offering series that meet the taste of each customer (Johnson, 2018). The success of the CRM giants has one thing in common: the adoption of Big Data technologies. Amazon and Netflix use customer data to be fair in their proposals by exploiting each piece of information such as the time spent on a page; products purchased or put in the basket, clicks or ratings. Therefore, it is possible to anticipate the needs of the customers and to put forward an individualized experience.

\subsection{Analytical CRM}

Based on activities and the nature of the work CRM system are generally categorized into three main categories: operational, collaborative, and analytical CRM. The operational CRM automates sales and marketing to generate leads of customer contacts within the CRM. The collaborative shared data between departments to achieve strategic goals and objectives. However, the analytical is responsible for enhancing business status based on decision provided from customer data. Figure 2 shows that the operational and analytical CRM is tightly coupled with data mining and business plans. In today's business world, new technologies are enabling business organizations to target individual customers or market segments more precisely. Simultaneously, new marketing techniques have made it possible to concentrate on more customer-focused perspectives. All of these factors are influencing the companies to increasingly embrace CRM as one of the significant elements of a corporate plan (Gurău et al., 2003).

Analytical CRM is the process of synthesizing and interpreting operational data for optimizing customer interactions, identifying opportunities, and managing business performance. In order to implement intelligent personalization, analytical CRM can help by providing essential insights into customer behavior which is accomplished by capturing, storing, processing, interpreting, and reporting of customer data (Goel, 2014). As pointed out by Ranjan \& Bhatnagar (2011), analytical CRM can solve many business issues, like achieving increased sales, providing better responses to customer queries through telephone, emails, and direct mail. It also helps companies identify their most profitable customers and influence them to get their products or services, as well as find future customers.

According to Al-Mudimigh et al. (2011), the critical success factors of analytical CRM are sales management, relationship management, opportunity management, and use of technology. The internet has forced companies to shift their marketing focus from the traditional process of mass-marketing to a new approach to one-to-one marketing. Today's consumers are becoming more sophisticated and informed, and hence, the companies are required to offer their products and services as per the needs of the customers. Businesses must store transaction records of the customers in an online system, which can also help interact with the customers precisely and consistently (Rygielski et al., 2002). 


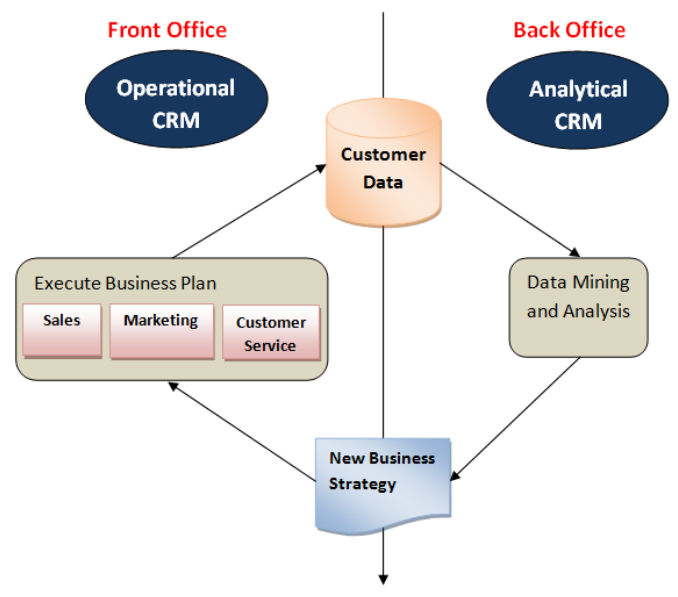

Figure 2. Relationship between operational and analytical CRM

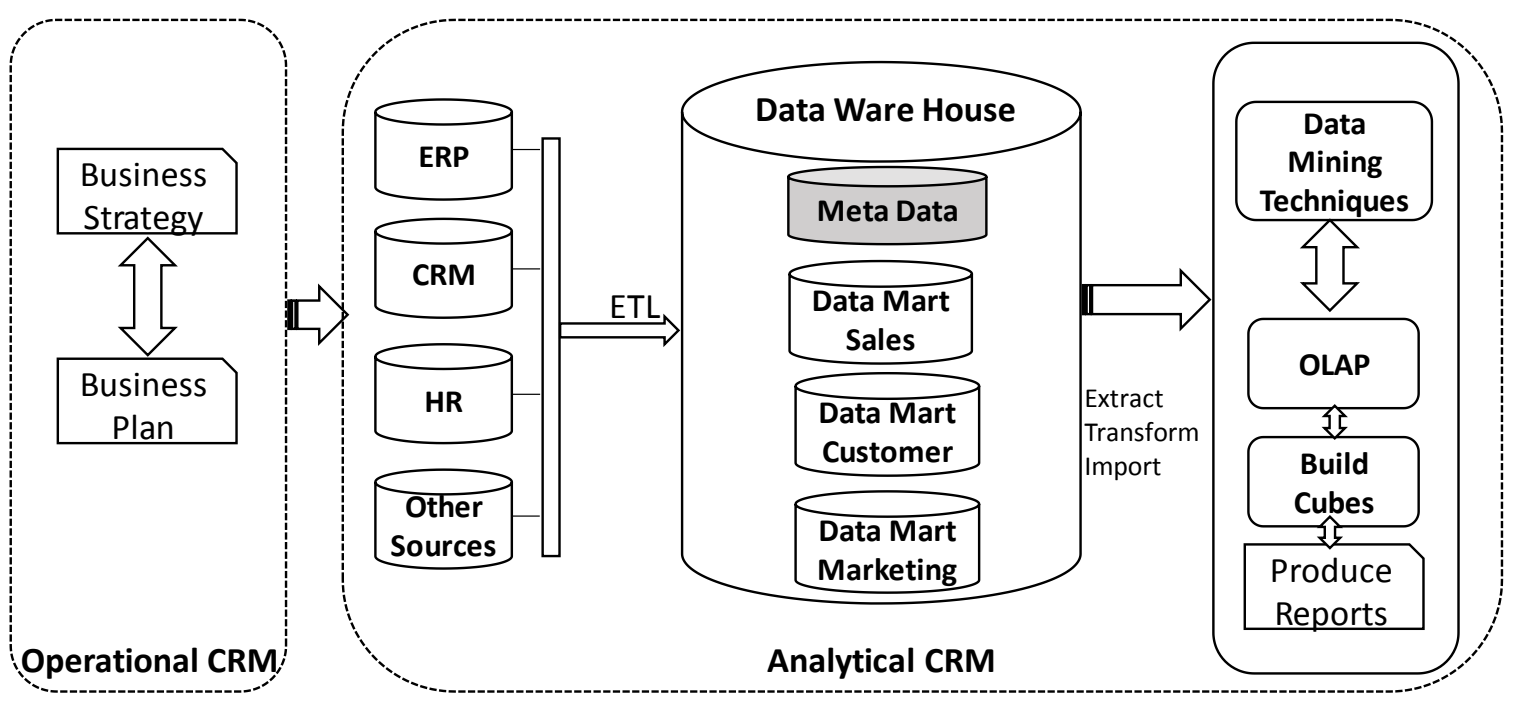

Figure 3. Proposed Framework

Collecting behavior data and customer demographics also make it possible to ensure precision targeting, which is the primary goal of analytical CRM. In business-to-business (B2B) environments, analytical CRM can be particularly useful, as it can help manage complicated pricing schemes, different customer contracts, and numerous transactions. Both the buying and selling companies can be benefitted through improved efficiencies and simplified procurement process using targeted product offers personalized business portals and customized catalogs. Overall authority and trust are also enhanced in the process.

\section{Proposed Framework}

Figure 3 depicts the proposed framework. The Analytical CRM consists of the following components: the data warehouse, a data mining module, and OLAP (online analytical processing) tools. The data warehouse provides an updated clone of the transactional data specifically for querying and reporting. Usually, the data warehouse is stored in a rational or multidimensional approach to ease query. It consists of several Data Marts that categorize data by subjects (e.g., sales, marketing) and Meta Data (data about data) which describes how data is saved in the warehouse. During the operational phase of CRM (or the front office), the business strategies are converted to executable business plans. During execution, the Analytical CRM comes into action. 
First, all related and needed data are loaded and saved into the data warehouse using Extraction Transformation Loading (ETL) tools. Then these data are extracted, transformed, and imported into online transaction processing (OLAP) servers. Next, based on data mining algorithms, the OLAP servers build the mined information cubes; therefore, producing patterns and decision support reports. The most common types of OLAP warehouse are Relational OLAP (ROLAP) and Multidimensional OLAP (MOLAP). The ROLAP stores data in relational database management systems (RBDMS) such as Oracle and Microsoft SQL server databases. It is characterized for provided simple queries often specialized for frequent use such as those of niche marketing campaigns. Although it is used to store much information, it can slow the OLAP server as it relies on SQL queries.

On the other hand, MOLAP is configured into slice-and-dice (OLAP cubes) functionality to performs more complex calculations repeatedly. However, it could hold less data as opposed to OLAP and is considered difficult to configure as it is related to different proprietary technologies. The Hybrid OLAP (HOLAP) is the combination of OLAP and MLAP where vital information is saved in ROLAP while summative information is saved in MOLAP.

Figure 4 depicts the most common information that is handled by OLAP into a CRM solution. As the figure shows the dimensionality of the OLAP increase as data is increased. Usually a three-dimensionality of data is used; however, dimensionality can grow up to 10 levels.

\section{Data Mining In CRM}

This paper focuses on data mining techniques as applied to analytical CRM. Data mining is defined as the science of extracting valuable information from large databases (Kargupta et al., 2004). According to(Zaker \& Hussien, 2017), data mining is the "process of extracting and presenting implicit knowledge from large volumes of databases for actionable decisions" (p. 28). It is the process of inferring essential business relationships by using raw data. By using sophisticated data analysis tools, data mining helps to find healthy relationships and patterns in the large data set. Tools used for discovering patterns can be mathematical, algorithms, statistical models, or different machine learning

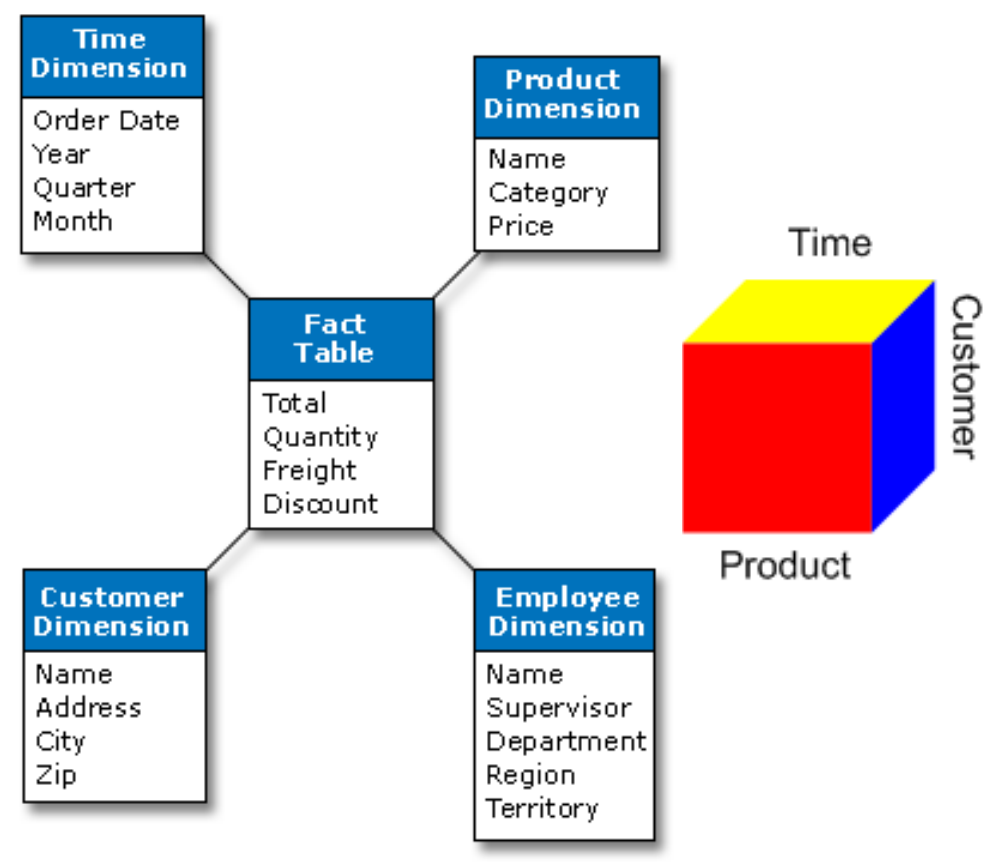

Figure 4. OLAP Structure

methods (Chopra et al., 2011).Results of data mining increase customers' loyalty and enhance their confidence and trust (Jayashree et al., 2011).

Businesses data mining techniques have many objectives. Attracting and acquiring new customers and analyze their purchase patterns over time. Moreover, data mining provides segment-based products for segment-based customers; therefore, adding value to the existing products or services. Ultimately, a company takes proactive actions following detected emerging trends in customer behavior in highly competitive business environments. Data mining has various techniques; we illustrate the main three of them in the context of CRM analytics. 


\subsection{Clustering}

Clustering is the technique of combining the customers with the same set of transactions or queries into one group, or the transactions with similar behavior into one group. For instance, customers with a job profile and residing in the same geographic area often demand a set of services, and it is possible to add them into the same group. Clustering technique can help a company find the solution of the 80/20 principle of marketing, i.e., identifying that $20 \%$ of the loyal customers who will contribute to $80 \%$ of the company's profit (Chopra et al., 2011). The clustering can be done in different ways, like using logistic regression, decision trees, weblog classification (Shim et al., 2012).

\subsection{Association}

Association is the technique of finding patterns by identifying the connection between two events triggered by customers. It helps the company make vital decisions regarding different marketing strategies, like pricing. For example, when a person buys a pen, it is highly likely that he/or she will buy the paper as well.

Hence, it is the job of the company to make sure that the customer can find these two products easily by placing these adjacent to each other in the store. At the same time, by identifying patterns through association technique of data mining, the company can offer discounts when someone buys these products together (Ayyagari, 2019).

\subsection{Forecasting}

Companies use data mining forecasting technique for making reasonable predictions regarding future customer activities by discovering different patterns. For example, if a person took a loan for buying a car five years ago, it is highly likely that he/she will go for retaking loan for buying another brand-new car. The technique can make future predictions intelligently and automatically by using decision trees or clusters and association rules. Companies can find loyal customers by analyzing their behavior or the transactions they make and take the necessary measures accordingly (Mau et al., 2018).

\section{Evaluation and Discussion}

We illustrate the proposed framework to two CRM experts. They agreed that the proposed framework is abstract enough to be understood by their peers. After interviewing them serval times, we reach an agreement that is no one single way to explain analytical CRM, and further work may be needed to add deep learning techniques to the proposed framework. Experts were worried about the level of abstraction of the model and the need to relate to other solutions and cloud solutions of CRMs. The tools and techniques of data mining can be immensely helpful for businesses to become more customer oriented. Using customer lifecycle can help to apply data mining to analytical CRM, where it tells what information is available on the 'input' side of data mining. However, this customer lifecycle also reveals what is likely to be interesting on the 'output' side. Data mining can predict prospects of becoming active customers, the probable time for them to continue being active customers, and how likely they will leave (Rygielski et al., 2002).

The followings are the necessary steps in implementing data mining in the effective analytical CRM process(Gupta \& Aggarwal, 2012):

1. Defining Business Problem

2. Building Marketing Databases

3. Exploring Data

4. Preparing Data for Modeling

5. Building Model

6. Evaluating Model

7. Deploying Model and Extracting Results

Through using data mining techniques in the analytical CRM process, the companies can successfully improve the retention rates of the customers, as well as improve their attraction, response rates, and cross-selling (Zineldin, 2006). Eventually, companies can increase the value of the customers, foster improved loyalty, and attract the right customers. Business organizations can achieve greater success if they can implement analytical CRM by adopting the techniques of data mining (Zaker \& Hussien, 2017). The data mining techniques can help the company improve their relationship with the customers and can have a better strategic vision. The techniques of data mining can be efficiently used for customer segmentation and providing useful results for marketing purposes (Gurău et al., 2003).

\section{Challenges}

An essential challenge for implementing data mining in analytical CRM is to ensure data privacy(Palmatier \& Martin, 2019) and security(Fernando et al., 2018). Data mining techniques may add to the risk of invading customer privacy by using their information without their wishes, or sometimes to their detriment. 
Businesses often gather transactional data of customers when a business transaction takes place. They gather information like the name of the product, location, quantity, and the time of purchase, and then this customer data is turned into customer profiling information through data mining which is often unknown to the customers, who may not welcome the company's initiatives to use those data and send personalized campaigns to them periodically (Rygielski et al., 2002). Often the transactional or purchasing behavior of the customers is considered while studying customer behavior, which may sometimes lead to wrong conclusions, as this behavior may often vary depending on the customer. Another challenge for implementing data mining in analytical CRM is to manage diverse data types, which often calls for the integrated mining of heterogeneous and diverse data. The ICT experts often have to manage data which comes in different forms, like temporal data (like weblogs), demographic data, text (emails, blogs, customer reviews, chatroom data), audio (through recorded phone or conversation with customers) (El-Zehery et al., 2014). It is a daunting task for the data miners to manage these varieties of data while extracting useful customer information.

In analytical CRM, the required data may come from multiple sources, like from different departments of the company. Again, many new patterns span multiple data sources. Hence, before an actual data mining exploration can start, it is necessary to integrate this data, which can be a significant challenge. Consequently, the patterns discovered through data mining are needed to be tested using rigorous statistical procedures before they can be identified as accepted results which can be a vital issue when particular actions are taken based on those results(El-Zehery et al., 2014). Another critical challenge is to tackle legal issues that define what data can be gathered and what actions are permissible(Kumar \& Reinartz, 2018a). Particularly in some countries, it is not permissible to use data for those purposes that are different from those for which they are gathered. Legal issues often make it difficult for IT specialists to use data mining as and when needed.

\section{Recommendations}

In order to solve the privacy issues of customer information, the companies should be alert and try to disclose to their customers the types of information they are seeking and the way this information can be used which will enhance the trust of the customer on the company and also make them more loyal shortly. Companies must also use additional encryption procedures while keeping the identity information of the customers. Furthermore, businesses must be aware that they must use the data mining technology responsibly so that a balance can be achieved between economic benefits and privacy rights. The companies must also engage experienced and skilled IT professionals to handle the data mining process for CRM. Otherwise, it will not be possible to handle critical issues related to data mining, and the successful and effective management of customer relationship will not be possible at the end. The experienced and certified professionals will be able to translate business needs into software modules effectively, which is vital for implementing data mining techniques in CRM. At the same time, companies must also focus on investing in training to empower the employees or the end users so that they can execute the business processes effectively using the data mining techniques used for analytical CRM. They should also be trained about how the software functionalities and features can be used. The employees must have clear conceptions about how these processes can help the company serve the customers better.

\section{Conclusion}

Business organizations can be able to offer the right product to the right set of customers by judicially selecting the appropriate data mining technique and implementing it correctly, which may also ensure better customer relationship management. Data mining techniques can be vital for business organizations. Business use data mining to solve different problems by finding the correlations, associations, and patterns in the business information that might help to find the real customers, reach them efficiently, and provide the goods and services according to their needs. This paper proposed a framework that heights the interaction between analytical CRM components to achieve company goals and touch their strategies. The proposed framework provides simplified concepts of data mining for decision makers, and it helps to reduce training time for administrators. Therefore, the proposed framework helps managers to make their company a profitable business.

\section{References}

Al-Mudimigh, A. S., Ullah, Z., \& Saleem, F. (2011). Successful implementation of CRM: The role of data mining [Successful implementation of CRM: The role of data mining]. In International Conference on Computer Engineering and Applications IPCSIT (Vol. 2, pp. 424-429).

Anshari, M., Almunawar, M. N., Lim, S. A., \& Al-mudimigh, A. (2018). Customer relationship management and big data enabled: personalization \& customization of services [Customer relationship management and big data enabled: personalization \& customization of services]. Applied Computing and Informatics. 
Ayyagari, M. R. (2019). Integrating Association Rules with Decision Trees in ObjectRelational Databases [Integrating Association Rules with Decision Trees in ObjectRelational Databases]. International Journal of Engineering Trends and Technology, 67(3), 102-108.

Berson, A., \& Smith, S. J. (1997). Data warehousing, data mining, and OLAP [Data warehousing, data mining, and OLAP]. McGraw-Hill, Inc.

Bhat, S. A., \& Darzi, M. A. (2016). Customer relationship management: An approach to competitive advantage in the banking sector by exploring the mediational role of loyalty [Customer relationship management: An approach to competitive advantage in the banking sector by exploring the mediational role of loyalty]. International Journal of Bank Marketing, 34(3), 388-410.

Chatfield, A. T., \& Reddick, C. G. (2018). Customer agility and responsiveness through big data analytics for public value creation: A case study of Houston 311 on-demand services [Customer agility and responsiveness through big data analytics for public value creation: A case study of Houston 311 on-demand services]. Government Information Quarterly, 35(2), 336-347.

Chopra, B., Bhambri, V., \& Krishan, B. (2011). Implementation of data mining techniques for strategic CRM issues [Implementation of data mining techniques for strategic CRM issues]. International Journal of Computer Technology and Applications, 2(4), 879-883.

El-Zehery, A. M., El-Bakry, H. M., El-Ksasy, M. S., \& Mastorakis, N. (2014). Applying Data Mining Techniques for Customer Relationship Management [Applying Data Mining Techniques for Customer Relationship Management]. Recent Advances in Computer Engineering, Communications and Information Technology, 398-406.

Fernando, Y., Chidambaram, R. R. M., \& Wahyuni-TD, I. S. (2018). The impact of big data analytics and data security practices on service supply chain performance [The impact of big data analytics and data security practices on service supply chain performance]. Benchmarking: An International Journal, 25(9), 4009-4034.

Følstad, A., Skjuve, M., \& Brandtzaeg, P. B. (2018). Different Chatbots for Different Purposes: Towards a Typology of Chatbots to Understand Interaction Design [Different Chatbots for Different Purposes: Towards a Typology of Chatbots to Understand Interaction Design]. In International Conference on Internet Science (pp. 145-156).

Goel, S. (2014). Customer relationship management: An Indian perspective [Customer relationship management: An Indian perspective]. International Journal of Marketing and Technology, 4(11), 58.

Gupta, G., \& Aggarwal, H. (2012). Improving customer relationship management using data mining [Improving customer relationship management using data mining]. International Journal of Machine Learning and Computing, 2(6), 874.

Gurău, C., Ranchhod, A., \& Hackney, R. (2003). Customer-centric strategic planning: Integrating CRM in online business systems [Customer-centric strategic planning: Integrating CRM in online business systems]. Information Technology and Management, 4(2-3), 199-214.

Hamid, A., Ahmad, R. M. T. R. L., Majudi, S., Hassan, W. A. W., Ismail, W. H. B. W., Setik, R., \& Hashim, M. (2018). Social CRM Analytics Model on Malaysian Institutes of Higher Learning (IHLs) [Social CRM Analytics Model on Malaysian Institutes of Higher Learning (IHLs)]. In 2018 3rd Technology Innovation Management and Engineering Science International Conference (TIMES-iCON) (pp. 1-5).

Hargreaves, I., Roth, D., Karim, M. R., Nayebi, M., \& Ruhe, G. (2018). Effective customer relationship management at atb financial: A case study on industry-academia collaboration in data analytics [Effective customer relationship management at atb financial: A case study on industry-academia collaboration in data analytics]. In Highlighting the Importance of Big Data Management and Analysis for Various Applications (pp. 45-59). Springer.

Hu, K., Li, Z., Liu, Y., Cheng, L., Yang, Q., \& Li, Y. (2018). A Framework in CRM Customer Lifecycle: Identify Downward Trend and Potential Issues Detection [A Framework in CRM Customer Lifecycle: Identify Downward Trend and Potential Issues Detection]. ArXiv E-Prints.

Jayashree, S., Shojaee, S., \& Pahlavanzadeh, S. (2011). A critical analysis of Customer Relationship Management from strategic perspective [A critical analysis of Customer Relationship Management from strategic perspective]. In International Conference on E-business, Management and Economics. Hong Kong: IACSIT Press (Vol. 3, pp. 340-345).

Johnson, D. (2018). From Networks to Netflix: A Guide to Changing Channels [From Networks to Netflix: A Guide to Changing Channels]. Routledge.

Kargupta, H., Joshi, A., Sivakumar, K., \& Yesha, Y. (2004). Data mining: next generation challenges and future directions [Data mining: next generation challenges and future directions]. Aaai Press. 
Kaur, E. S., \& Singh, E. H. (2018). An Enhanced Data Mining Technique to improve the CRM using Association Rule Mining [An Enhanced Data Mining Technique to improve the CRM using Association Rule Mining]. International Journal of Engineering Science, 18650.

Kumar, V., \& Reinartz, W. (2018a). CRM Issues in the Business-To-Business Context [CRM Issues in the BusinessTo-Business Context]. In Customer Relationship Management (pp. 265-283). Springer.

Kumar, V., \& Reinartz, W. (2018b). Customer Analytics Part II [Customer Analytics Part II]. In Customer Relationship Management (pp. 101-134). Springer.

Markovic, S., Iglesias, O., Singh, J. J., \& Sierra, V. (2018). How does the perceived ethicality of corporate services brands influence loyalty and positive word-of-mouth? Analyzing the roles of empathy, affective commitment, and perceived quality [How does the perceived ethicality of corporate services brands influence loyalty and positive word-of-mouth? Analyzing the roles of empathy, affective commitment, and perceived quality]. Journal of Business Ethics, 148(4), 721-740.

Marques, M. A., \& Costa, C. J. (2018). Social CRM analytics [Social CRM analytics]. In 2018 13th Iberian Conference on Information Systems and Technologies (CISTI) (pp. 1-6).

Mau, S., Pletikosa, I., \& Wagner, J. (2018). Forecasting the next likely purchase events of insurance customers: A case study on the value of data-rich multichannel environments [Forecasting the next likely purchase events of insurance customers: A case study on the value of data-rich multichannel environments]. International Journal of Bank Marketing, 36(6), 1125-1144.

Nam, D., Lee, J., \& Lee, H. (2019). Business analytics use in CRM: A nomological net from IT competence to CRM performance [Business analytics use in CRM: A nomological net from IT competence to CRM performance]. International Journal of Information Management, 45, 233-245.

Ngai, E. W. T., Xiu, L., \& Chau, D. C. K. (2009). Application of data mining techniques in customer relationship management: A literature review and classification [Application of data mining techniques in customer relationship management: A literature review and classification]. Expert Systems with Applications, 36(2), 2592-2602.

Palmatier, R. W., \& Martin, K. D. (2019). Customer Data Privacy: Why Every Marketer Should Care [Customer Data Privacy: Why Every Marketer Should Care]. In The Intelligent Marketer's Guide to Data Privacy (pp. 3-20). Springer.

Plakoyiannaki, E., \& Saren, M. (2006). Time and the customer relationship management process: conceptual and methodological insights [Time and the customer relationship management process: conceptual and methodological insights]. Journal of Business \& Industrial Marketing, 21(4), 218-230.

Ranjan, J., \& Bhatnagar, V. (2011). Role of knowledge management and analytical CRM in business: data mining based framework [Role of knowledge management and analytical CRM in business: data mining based framework]. The Learning Organization, 18(2), 131-148.

Rygielski, C., Wang, J. C., \& Yen, D. C. (2002). Data mining techniques for customer relationship management [Data mining techniques for customer relationship management]. Technology in Society, 24(4), 483-502.

Shim, B., Choi, K., \& Suh, Y. (2012). CRM strategies for a small-sized online shopping mall based on association rules and sequential patterns [CRM strategies for a small-sized online shopping mall based on association rules and sequential patterns]. Expert Systems with Applications, 39(9), 7736-7742.

Tamayo, P., Berger, C., Campos, M., Yarmus, J., Milenova, B., Mozes, A., ... others. (2005). Oracle data mining [Oracle data mining]. In Data mining and knowledge discovery handbook (pp. 1315-1329). Springer.

Tiwari, S., \& others. (2018). Amazon: customer first approaches [Amazon: customer first approaches].

Tsiptsis, K. K., \& Chorianopoulos, A. (2011). Data mining techniques in CRM: inside customer segmentation [Data mining techniques in CRM: inside customer segmentation]. John Wiley \& Sons.

Zaker, R. A. L. I., \& Hussien, M. M. (2017). The Role of Data Mining on the Successful Customer Relationship Management [The Role of Data Mining on the Successful Customer Relationship Management]. International Journal of Management and Applied Science, (9), 28-32.

Zhu, X. (2019). Case XI: Amazon's DNA: Driving Technology Innovation in the Digital Economy [Case XI: Amazon's DNA: Driving Technology Innovation in the Digital Economy]. In Emerging Champions in the Digital Economy (pp. 289-311). Springer.

Zineldin, M. (2006). The royalty of loyalty: CRM, quality and retention [The royalty of loyalty: CRM, quality and retention]. Journal of Consumer Marketing, 23(7), 430-437. 